\title{
Mujer militar y política de defensa: reflexiones desde Ecuador y el Buen Vivir
}

\author{
Cristian Daniel Valdivieso*
}

\section{RESUMEN}

El presente trabajo busca analizar las manifestaciones, reproducciones y rupturas discursivas que experimentan las nociones de género a partir de las masculinidades militarizadas presentes en los documentos de defensa del Ecuador. El corpus de análisis está constituido por las políticas de defensa producidas entre 2002 y 2017, considerando el periodo presidencial de Rafael Correa (2007-20I7). La Constitución de 2008, con la inclusión de la filosofía indígena del Buen Vivir (Sumak Kawsay), permitió la promoción de políticas públicas direccionadas a alcanzar la equidad de género y la interculturalidad. Las instituciones castrenses se han mostrado especialmente reticentes a los cambios producidos por dichas medidas, generando una militarización de las políticas de género. Es decir, el potencial de cambio que las caracteriza ha sido contenido por la supremacía del ethos militar masculino. El efecto de esa contención - en un país que se autodenomina plurinacional, que reconoce la presencia de diversos pueblos en su territorio - necesita ser analizado, puesto que impacta directamente con las propuestas de inclusión social. Se argumenta que la militarización de elementos como la equidad de género y la interseccionalidad del Buen Vivir, además de corroer el potencial transformador de inclusión social, permite reproducir nuevas formas de manifestación de las masculinidades militarizadas en los documentos de defensa, actualizando las dinámicas que responden a la dicotomía masculino/femenino en un sentido dialéctico y negativo. Para el análisis se emplea una perspectiva de género feminista aliada al análisis del discurso de vertiente francesa, visando examinar las manifestaciones discursivas de las masculinidades militarizadas en los documentos de defensa.A partir del análisis se crearon tres categorías ilustrativas de la presencia de la mujer en los documentos de defensa: ciudadana parcial, ciudadana autorizada, mujer militar. Las tres representaciones muestran, en un antes y un después de las políticas de género, que las mujeres continúan vivenciando rechazo en los espacios militares, ocupando el lugar de un otro. Se concluye que las masculinidades militarizadas han experimentado una metamorfosis discursiva, mostrando el blindaje resistente y sutil del ethos militar masculino. En términos de estructura, el trabajo posee tres secciones. En la primera, se despliegan los instrumentos conceptuales para comprender la relación entre género y masculinidades. Enseguida, se desarrolla una breve descripción de la metodología utilizada. Finalmente, se aplica el dispositivo de análisis a la localización de las manifestaciones de las masculinidades militarizadas en los documentos.

\section{Palabras clave}

Ecuador; masculinidades militarizadas; documentos de defensa; Sumak Kawsay; género.

\section{TitLe}

Military woman and defense policy: reflections from Ecuador and Buen Vivir

\section{Extended Abstract}

Since 2007, after the election of the economist Rafael Correa Delgado for president of the Republic of Ecuador, the country has been experiencing a series of ideological, structural and political changes. A Constitutional Assembly, demanded by a Popular Consultation, materialized Correa's project of "homeland refoundation" (Ulloa, 2020, p. 19). In 2008, once the Constitution had been drafted, 63,93\% of the voting population said "Yes" to the new Constitution, thus establishing what would be a turning point in national politics.

On the one hand, until the fall of Colonel Lucio Gutiérrez (2003-2005), the country had undergone turbulence during

DOI:

https://doi.org// 0.15366/relacionesinternacionales2022.49.006

Formato de citación recomendado:

VALDIVIESO, Cristian Daniel (2022). "Mujer militar y política de defensa: reflexiones desde Ecuador y el Buen Vivir", Relaciones Internacionales, $\mathrm{n}^{\circ}$ 49, pp. III-I32.

* Cristian Daniel VALDIVIESO, Doctorando en el Programa Interinstitucional de Postgrado en Relaciones Internacionales "San Tiago Dantas" (UNESP, UNICAMP, PUC-SP). Investigador del IARAS-Núcleo de Estudios de Género del Grupo de Estudios de Defensa y Seguridad Internacional (GEDES-UNESP). Contacto: cristian. valdivieso@unesp.br

Recibido: |4.09.202|

Aceptado: 25.01.2022 
the nineties due to significant political-institutional instability. There were three political leaders toppled in total; an armed conflict with its neighbor country, Peru; and a deep economic crisis that led the country to embark on dollarization. Correa's presidency, on the other hand, lasted ten years (2007-2017), after which time he left one of his vice-presidents Lenín Moreno as successor (20I7-202I). In addition, despite the corruption during his government, he continues to lead the second largest political party, as can be seen in the 2021 elections.

His Plan of Government, called 'Plan Nacional para el Buen Vivir', introduced the indigenous worldview of Sumak Kawsay. Translated from quichua language as Buen Vivir, this philosophy enabled the adoption of social inclusion measures, the enlargement of minority rights, including the expansion of the liberal juridical anthropocentric concept, by offering nature rights (Hernández, 2017). Sumak Kawsay means "life in its fullness $[\ldots]$ in its material and spiritual excellence $[\ldots]$ in its inner and outer balance of the community" (Macas, 2010, p. 14).

Based on this philosophy, Ecuador started moving towards social change, which was impossible without the inclusion of gender equality (Zaragocín, 2017, p. 64). In that sense, many public policies have been planned, creating debates on economic, political and social issues (Acosta, 20I2;Acosta y Cajas-Guijarro, 2018; Hernández, 20I7; Radcliffe, 20 I7). Furthermore, these policies targeted one of the most hermetic institutions: the Armed Forces.

In this respect, this paper aims to analyze the discursive reproductions and disruptions in gender categories (masculine and feminine) based on an analysis of Ecuadorian defense documents. The masculinities constitute a gender category that reflects the subjugation of the feminine by the masculine, and is connected to a superiority associated with strength, rationality, command, in opposition to feminine values (weakness, emotionality, anarchy) (Hooper, 1999). Nevertheless, masculinities are not personal characteristics concerning individuals. Instead, they should be understood as configurations produced by social actions in a particular context (Connell y Messerschmidt, 2005, p. 832). In this paper, Maya Eichler's militarized masculinities (MM) concept is used as a reference to the stereotypical masculine characteristics created by the exacerbation of virility in military rituals (military service, combat) (Eichler, 20I4, pp. 83-85). The author highlights that the MM are regularly and dynamically produced, making necessary an analysis on its features. Therefore, it is used to identify discursive and ideological formations and interdiscourses associated with gender notions present in the documents through a post-structural feminist approach and a discourse analysis methodology.

Gender equality constitutes an unavoidable issue in contemporary democracies and consequently the inclusion of women in the Ecuadorian Armed Forces is an ongoing challenge. Recent studies on the integration of women in the military demonstrate that public policies, mainly regarding gender equality and interculturality, have been militarized (Zaragocín, 20 I8, p. 436). In other words, the potential for social change has been lost. From this fact, this paper argues that the militarization of gender equality, besides undermining the transformative potential of social inclusion, allowed the reproduction of new manifestations of militarized masculinities in the defense documents, updating the dynamics based on a dialectic and negative masculine/feminine dichotomy.

Furthermore, the existence of a gap in the Ecuadorian security and defense literature is identified; despite the increase of women in the military, studies on this phenomenon remain incipient (Chacón, 20I4; Iturralde, 20I5; Morales et al., 2017; Zaldumbide, 2020; Zaragocín, 2018). Issues concerning military masculinities, hegemonic masculinity in these places and in Ecuadorian society - and their discursive reproductions, continuities and resistances - constitute a fertile ground for the analysis of the consequences of militarization for social inclusion. This paper fills this gap by analyzing the transformation in militarized masculinities in national defense discourse, and it does so through innovative methodological resources that allow a critical perspective on the results of the policies implemented since 2007.

In terms of methodology, a framework of analisis is used consisting of defense documents published from 2002 to 2017, namely: Libro Blanco de Defensa (2002, 2006),Agenda Política de Defensa (2009-20I3 and 20I4-20I7), Política de Género de las Fuerzas Armadas del Ecuador (2013) and the Cartilla de Género Fuerzas Armadas del Ecuador (2017).This framework refers to the year of 2002 due to the release of the first Libro Blanco during Gustavo Noboa's administration (2000-2003). This permits us to determine to what extent the inclusion of gender politics was an unavoidable issue in national defense politics during the documents' transition.

The body of analysis is addressed through the combination of a discourse analysis and a post-structural feminist perspective on gender, using Laura Shepherd's theoretical lens. The connection between these methodologies permits the identification of the ways that gender manifests itself as an element of power in discourses. It is highlighted how the post-structural feminist perspective allows us to question how the texts signify, enabling the realization of profound analyses that address the documents' discursive meanings (Shepherd, 2010, p. 9). Discourse should be understood as "word in motion", whose purpose is the production of effects of meaning (Orlandi, 20 I2, p. I5). Discourse is represented by oral and written word, and symbols that dispute meanings in subjective and ideological fields (Brandão, 20I2, p. 9). For this study, the texts that form the body of analysis are considered discourses. In this way, discourses are understood as neither transparent nor inert (Orlandi, 2012 , p. I5), but dynamic and contingent.

Besides the introduction and the final considerations, the work has three sections. The first section presents the conceptual tools that will be used to understand the relation between gender and masculinities. After that, a brief description of the methodology employed in the study is developed. Finally, the analysis is conducted on the manifestations of militarized masculinities in the documents. The work finishes by presenting a final argument, that is: besides undermining the transformative potential of social inclusion, the militarization of gender equality allows for the reproduction of new manifestations of militarized masculinities in the defense documents. The dynamics are updated based on a dialectic and negative masculine/feminine dichotomy.

Through this analysis three illustrative images of women's presence in the defense documents were created:"partial citizen", "authorized citizen" and "military woman". The three representations show, in a "before" and "after" comparison of gender politics, that women continue experiencing rejection in military spaces, being the "Other", and inherently a stranger to the ideal of militarized masculinity that prevails in the barracks. The conclusion is that militarized masculinities have experienced a discursive metamorphosis, demonstrating the subtle and resistant armor of the masculine military ethos.

\section{KEYWORDS}

Ecuador; militarized masculinities; defense documents; Sumak Kawsay; gender. 
La elección de Rafael Correa como presidente de la República del Ecuador, en 2006, ha sido considerada como un divisor de aguas' de la política en el país. Por un lado, la década de los noventa constituyó un momento de crisis de representación con un total de tres presidentes derrocados y una constante pugna de poder ${ }^{2}$. Ejemplo de ello fue el impedimento por parte del Congreso Nacional de que la vicepresidenta de Abdalá Bucaram, Rosalía Arteaga, asumiese el liderazgo del país, en 1997, como le correspondía constitucionalmente. Por otro lado, Rafael Correa gobernó durante diez años, llevó a cabo una Asamblea Constituyente, y planteó una serie de reformas en materia económica, política y social. Pese a los polémicos casos de corrupción durante su gobierno y de haber sido sentenciado a ocho años de prisión, mientras reside fuera del Ecuador, continúa siendo el líder de la segunda mayor fuerza política, como se ha evidenciado en las elecciones ${ }^{3}$ del año 2021 .

Con su Plan de Gobierno, bajo la idea de una Revolución Ciudadana, Correa puso en marcha el proyecto de "refundación del Estado", iniciando por la convocatoria a una consulta popular que se realizó el día 15 de abril de 2007 (Ulloa, 2020, p. 19). De esa forma, se dio paso a la instalación de una Asamblea Constituyente para redactar una nueva Carta Constitucional. En ella, proyectos críticos y alternativos al modelo económico neoliberal, dominante desde la década de los ochenta, fueron insertados bajo una propuesta de inclusión social, interculturalidad, igualdad de género y ampliación de derechos sociales. La nueva Constitución, además, anunciaba su meta de "alcanzar el buen vivir, el sumak kawsay" (Ecuador, 2008, p. I5).

La inserción del Sumak Kawsay, traducido del quichua como Buen Vivir, trajo consigo la ampliación de la concepción antropocéntrica jurídica liberal al otorgar derechos a la naturaleza (Hernández, 20 I7, p. 28). Por Sumak Kawsay debe entenderse "la vida en plenitud [...] en excelencia material y espiritual [...] en el equilibrio interno y externo de una comunidad" (Macas, 20 I0, p. 14). Al introducir esa filosofía ancestral indígena, el Estado ecuatoriano se encausaba hacia la búsqueda de una armonía entre sociedad y naturaleza.

El Buen Vivir contiene un potencial de reedificación social, impensable sin la igualdad de género (Zaragocín, 2017, p. 17). Hacia ese horizonte se proyectaron diversas políticas públicas, las cuales han sido objeto de estudio amplio en diversos frentes: socioeconómico, modelo postneoliberal (Blanco y Aguiar, 2020; Hernández, 2017; Radcliffe, 2017), o la inauguración de una economía solidaria no occidental (Acosta, 2012; Acosta y Cajas-Guijarro, 20I8). Además, las políticas emitidas llegaron a una de las instituciones más herméticas: las Fuerzas Armadas (Chacón, 20I4; Herrera, 2020; Iturralde, 20I 5; Zaragocín, 20I7).

Estudios recientes sobre los espacios militares ecuatorianos muestran que las políticas públicas y decretos presidenciales para alcanzar la equidad de género han sido militarizados (Zaragocín, 20 I8, p.436). Entendiéndose militarización como un proceso de control y sofocamiento,

\footnotetext{
Parte de la literatura defiende que la llegada de Correa a la presidencia, con su proyecto de Revolución Ciudadana, constituye uno de los grandes marcos tras al retorno democrático, en 1979 (Basabe-Serrano, 2013, p. 168).

Término comúnmente utilizado en el país para referirse a los conflictos de interés político.

El candidato del correísmo,Andrés Arauz, pasó a segunda vuelta junto al representante de la derecha, Guillermo Lasso. Los resultados fueron del $47,64 \%$ contra el $52,36 \%$ a favor de Lasso (Ecuador, 2021 ).
} 
por medio de los principios que rigen a las instituciones militares, del potencial de cambio presente en las políticas de inclusión social (Enloe, 2000, p. 291).

Pese al incremento de mujeres en los cuarteles, los estudios son aún incipientes en el caso ecuatoriano,versando principalmente sobre el proceso de inserción de esas mujeres (Chacón,20 I4; Iturralde, 20I5;Tellería, 2009) y las principales dificultades que enfrentan para ocupar los espacios conquistados o para ampliarlos (Herrera, 2020; Orbe, 2016; Zaragocín, 2018). Cuestiones sobre masculinidades militares, masculinidad hegemónica en esos espacios y en la sociedad ecuatoriana - y sus reproducciones, continuidades y resistencias discursivas - constituyen un campo fértil para el análisis de las consecuencias de la militarización de la inclusión social. El presente trabajo se adentra en ese terreno para analizar las metamorfosis de las masculinidades militarizadas en el campo discursivo de la defensa nacional. Así, se aporta en la identificación de vacíos en la literatura sobre seguridad y defensa del Ecuador mediante el empleo de recursos metodológicos que permiten abordar de forma crítica, y desde una perspectiva de género, las políticas de género implementadas desde el 2007.

Dado ese contexto, el presente trabajo busca analizar las reproducciones y rupturas discursivas que experimentan las nociones de género (masculino y femenino) a partir del análisis de las masculinidades militarizadas que se manifiestan en los documentos de defensa del Ecuador. Las masculinidades constituyen una categoría de género que reflejan la sobreposición de lo masculino a lo femenino, atribuyendo a aquel características como fuerza, racionalidad, orden, todas ellas construidas bajo una lógica de antagonismo de lo femenino (debilidad, emotividad, anarquía) (Hooper, 1999, p. 478). No obstante, no se deben confundir las masculinidades con características personales de individuos, sino que deben ser entendidas como configuraciones de género determinadas por factores contextuales, los cuales sirven como elementos organizativos de las acciones sociales (Connell y Messerschmidt, 2005, p. 836). En este trabajo se utiliza la noción de masculinidades militarizadas, de Maya Eichler, como referencia a rasgos masculinos estereotipados creados por la exacerbación de la idea de hombría en rituales militares (servicio militar, entrenamientos físicos) (Eichler, 20I4, pp. 83-85). La autora destaca que las masculinidades militarizadas se producen de forma contingente y dinámica, siendo necesario analizar las peculiaridades bajo las cuales emergen.Así, por medio de un abordaje feminista postestructuralista, afiliado al análisis del discurso de vertiente francesa, se localizarán las formaciones discursivas, ideológicas y los interdiscursos a los cuales las nociones de género presentes en los documentos están vinculadas.

El corpus de análisis está constituido por las políticas de defensa producidas entre 2002 y 2017, periodo presidencial de Rafael Correa (2007-2017): Libro Blanco de Defensa $(2002,2006)$, Agenda Política de Defensa (2009-20I3 y 2014-2017), Política de Género de las Fuerzas Armadas del Ecuador (20I3), Cartilla de Género Fuerzas Armadas del Ecuador (20I7). El recorte se remite al año 2002 debido al lanzamiento del primer Libro Blanco de la Defensa ${ }^{4}$ durante la gestión de Gustavo Noboa (2000-2003). Esto permite visualizar en qué medida la inclusión de políticas de género se volvió, en la transición de los documentos, un elemento ineludible de las políticas de defensa nacional.

Si bien los Libros Blancos son el reflejo de la implementación de medidas de transparencia en materia de defensa, los documentos carecen de procesos abiertos de discusión, autocrítica y debate con la sociedad civil (Tellería, 2009, p. 66). 
Omitiendo esta introducción y las consideraciones finales, el trabajo posee tres secciones. En la primera, se despliegan los instrumentos conceptuales para comprender la relación entre género y masculinidades. Enseguida, se desarrolla una breve descripción de la metodología utilizada. Finalmente, se aplica el dispositivo de análisis a la localización de las manifestaciones de las masculinidades militarizadas en los documentos. El trabajo finaliza con algunas ideas sobre el argumento, a saber: que la militarización de la equidad de género, además de corroer el potencial transformador de inclusión social, permite reproducir nuevas formas de manifestación de las masculinidades militarizadas en los documentos de defensa, actualizando las dinámicas que responden a la dicotomía masculino/femenino en un sentido dialéctico y negativo.

\section{Género y seguridad internacional: una alianza compleja}

La evolución de los estudios feministas en las Relaciones Internacionales puede ser entendida de forma gradual a partir de sus críticas (Peterson, 2004, p. 36). Desde denuncias iniciales sobre la aparente neutralidad de conceptos como poder, anarquía, estado hasta formulaciones complejas que involucran la concepción del género como una construcción social (Hansen, 20 l 0; Narain, 20 I4; Sjoberg, 2009; Tickner, 1997; Whitworth, 1997). A lo largo de ese camino, perspectivas vinculadas al orden posmodernista han dado luz a vertientes feministas postcoloniales, decoloniales, críticas y postestructuralistas, mostrando el perfil interseccional bajo el cual operan las relaciones de poder asociadas al género (Hansen, 2010, Pp. 17-18).

Por género debe entenderse los "comportamientos socialmente asimilados, actividades repetidas y expectativas idealizadas que permiten asociar y distinguir entre los papeles de género prescritos de masculinidad y feminilidad" (Runyan y Peterson, 20I4, p. 2). El género, argumenta Spike Peterson, es una categoría que se encuentra en el ADN de las sociedades, impregnando todas las relaciones sociales y sus medios, tal como el lenguaje y el discurso, que impactan en la formulación de políticas. Esta sección mostrará cómo esa compleja alianza entre estudios de género y de seguridad internacional se ha ido tejiendo y ha conquistado, poco a poco, territorios militares cuyo ethos ${ }^{5}$ se encuentra permeado por dinámicas militarizadas y masculinizadas.

\section{I.I. Edificaciones analíticas del género en la guerra}

La identificación del género como factor omnipresente no se resume únicamente a su importancia para la formación de las relaciones sociales, sino también a su impacto y proyección hacia las estructuras institucionales. Algunos neologismos abordan este fenómeno al mencionar que ciertos espacios se encuentran generificados, denotando que se encuentran estructurados con base en una asimetría entre masculino y femenino (Hooper, 1999, pp. 479-480). Es decir, diversas características son asociadas a ambas categorías, estableciendo una dinámica relacional del género (Scott, 20 I8, p. 49).Así, elementos como orden, racionalidad, cultura, interno, público se construyen en función de la negación de sus opuestos (anarquía, emoción, naturaleza, externo, privado). Este orden relacional y dicotómico es, a su vez, asociado a la disputa entre masculino versus femenino.

Construcción de la imagen de sí de forma social y discursiva (Amossy, 20 I I, p. I0). En este caso, se emplea para entender la forma de ser de los militares. 
En los asuntos internacionales, esa dinámica es perceptible cuando se emplean atributos generificados para dar explicación a ciertos fenómenos y procesos. Por ejemplo, el espacio doméstico es comúnmente contrapuesto al orden de lo externo, aludiendo a la existencia de un espacio soberano y de otro marcado por la anarquía internacional. A simple vista no se percibe una relación de género, pero cuando se amplía el enfoque para el uso de la noción de naturaleza humana —como una concepción europea, basada en la figura del hombre blanco, propietario, heterosexual- se percibe la existencia de una perspectiva masculina (Tickner, 1997, p. 6/4). Esa perspectiva, a su vez, se encuentra dotada de una neutralidad otorgada por concepciones epistemológicas recortadas del Norte Global, propias de la modernidad occidental (Santos, 20I8, p. 26).

El manejo histórico de esas relaciones de género ha llevado a que lo masculino sea considerado como un elemento de orden superior a lo femenino, estableciéndose una relación de poder y dominación. Esas oposiciones establecen relaciones binarias y representaciones del mundo, como la antes citada, en las cuales lo interno constituye el imperio del estado, la ley, el orden y la racionalidad, mientras lo externo se traduce en la anarquía, la naturaleza a ser domada y dominada por medio de la cultura masculina.

El fenómeno de la guerra ha sido históricamente entendido como el producto de una conexión directa entre el hombre y el cometimiento de prácticas vinculadas a la violencia, atribuida a su aparente naturaleza humana de orden superior a lo femenino. Esa creencia se ha mostrado resistente a los análisis que señalan que la guerra es una práctica cultural histórica que depende de circunstancias específicas para su producción (Ferguson, 202 I, p. I I3; Garrido, 202 I, pp. 8283). Ante ello, diversas autoras feministas han planteado que la guerra es, en realidad, la práctica que ha favorecido a la construcción social de un hombre violento, víctima de ella y su verdugo, puesto que mismo en sociedades carentes de conflictos armados, son los hombres los principales perpetradores de actos violentos (Stern y Zalewski, 2009, p. 62I; True, 2020, p. 55).

Las críticas feministas, de ese modo, buscan lanzar luz sobre los elementos omitidos por la historia para dar protagonismo a las mujeres que han participado en procesos bélicos importantes. Pese a ello, las imágenes del guerrero mítico, recuperado de las mareas provenientes de la Antigua Grecia (Elshtain, 2005, pp. 303-304), persisten en los espacios militares contemporáneos que han optado por creer que las guerras han sido luchadas y ganadas únicamente por hombres (Grant, 1992, p. 83). Sin embargo, ignoran, como argumentan Sylvester y Elshtain, que muchas de esas narrativas son mentirosas, incompletas y fundamentadas en mitos estereotipados de masculinidad (Sylvester, 2015, p. 587).

Esa figura del ciudadano griego, como guerrero por excelencia, actualmente ocupa de forma conveniente las filas de los ejércitos contemporáneos y es constantemente reafirmada mediante rituales (servicio militar, desfiles militares). Es, además, la expresión de la necesidad de formar ciudadanos hombres como modelo de guerreros dispuestos a dar la vida por la madre patria. Vale observar cómo actúa el componente de género relacional al indicar que la patria, representada como una mujer y sometida al estereotipo de la fragilidad, requiere de permanente protección masculina (Via, 20I0, p. 43; Young, 2003, p. 20). 
Las evidencias son contrastantes cuando se observa la participación de las mujeres en eventos históricos como la Revolución Francesa, los procesos de independencia en América Latina, las dos Grandes Guerras del siglo XX y actuación en grupos irregulares (Aleksiévitch, 2016; Baaz y Stern, 2013; Chacón, 20 14; Elshtain, 2005; Sjoberg y Gentry, 2007). Actualmente, los efectos de las luchas feministas se han tornado ineludibles para repensar la democracia en Occidente, de esa forma, los ejércitos han ampliado la participación de mujeres, mostrando que las murallas hipermasculinizadas de dichas instituciones han comenzado a fracturarse.

\section{I.2. Masculinidades militarizadas: la doble muralla}

Entre los múltiples aportes de las teorías feministas podemos encontrar los temas relacionados a las masculinidades, pues no sería posible la emergencia de subáreas como los estudios de hombres y masculinidades, y toda una amplia literatura relacionada a la discusión de la masculinidad hegemónica, sin las constantes críticas emanadas de las vertientes feministas contemporáneas (Beasley, 2008; Connell, 2005, 20 I2; Connell y Messerschmidt, 2005; Via, 20 I0; Yang, 2020; Iglesias et al., 202I).

Las masculinidades deben ser entendidas como parte constituyente de la estructura relacional del género, configuran una serie de prácticas y simbolismos que se ajustan de forma contingente al contexto en el cual se manifiestan (Connell y Messerschmidt, 2005, p. 832). Episodios como la invasión de Irak, en 2003, ilustran el uso de las masculinidades como un elemento político para generar un efecto de feminización del adversario. Es decir, proyectar la imagen del enemigo como alguien débil, irracional e incapaz de actuar políticamente. Tal situación fue caracterizada como una "competencia masculina" entre George W. Bush y Saddam Husein (Tickner y Sjoberg, 2017, pp. 217-2I8).

En los cuarteles impera una dinámica similar al conjugar dos elementos clave que se refuerzan: la masculinidad y el militarismo. Las instituciones militares tienen la particularidad de incentivar ideales fantasiosos de guerreros míticos, así mantienen fresca la energía necesaria para decisiones explosivas, como el uso de la fuerza y la violencia. La noción de guerreros justos y almas bellas es alimentada constantemente por simbolismos, rituales y entrenamientos que exaltan la corporificación de la masculinidad como elemento exclusivo de los protectores para defender a los seres indefensos representados por las mujeres (Eichler, 20I4, p. 83; Elshtain, I 982, p. 34I).

Adicional a esa expresión de masculinidad, el militarismo, al ser un andamio de ideas, valores y creencias que moldan estructuras sociales e institucionales (Via, 2010, p. 45), dota de munición a la masculinidad exaltada en los cuarteles. Algunos de sus principios son: apoyar la resolución de conflictos, haciendo uso de la fuerza; considerar la naturaleza humana intrínsecamente conflictiva; valorizar relaciones jerárquicas como productoras de acciones más efectivas; creencia de que en tiempos de crisis son los cuerpos femeninos los que requieren de protección y que los hombres verdaderos serían aquellos que asumen la violencia armada (Enloe, 20I4, p. 3I). Enloe señala que la diseminación del militarismo ocurre de forma discreta, generalmente en "tiempos de paz" (p. 7), mediante un proceso denominado militarización. Ocurre, así, la naturalización de los ideales antes expuestos, expandiéndose hacia otras instituciones y configurando la mentalidad de la sociedad civil. A partir de esa doble muralla, las instituciones militares se revisten de un aura intocable de 
disciplina, moralidad, civismo y patriotismo, dotándolas de una amplia aceptación y respeto a nivel social. Sin embargo, el efecto más crudo de la complicidad entre la masculinidad y el militarismo radica en la insaciable confrontación con lo femenino, provocando la exclusión de las mujeres no solo en espacios militares, sino de la esfera pública en general.

Raewyn Connell argumenta que existen múltiples masculinidades hegemónicas dependiendo de las particularidades de los espacios analizados y que el efecto relacional del género no ocurre apenas entre masculino y femenino (Connell y Messerschmidt, 2005, p. 840). Precisamente, la masculinidad se torna hegemónica en la medida en que subyuga otras masculinidades y femineidades (aquellas asociadas al espectro LGBTQIA+). Los cuarteles producen y reproducen nociones de masculinidad hegemónica como un tipo puro inalcanzable, generando frustración en quien no consigue encarnar los ideales demandados (True, 2020, p. 55). En el caso de las mujeres, las exigencias en los cuarteles constituyen un oxímoron al exigir de ellas un desprendimiento de su feminilidad y al mismo tiempo pedir que usen tacos altos ${ }^{6}$ (Kronsell, 20 I 2;Via, 20I0).

Pese a las dificultades que obstaculizan los procesos de inclusión de las mujeres en las fuerzas armadas de diversos países, las políticas de género exhortadas por Naciones Unidas, a partir de la Resolución 1325/2000, han ocupado cada vez mayor terreno en las legislaciones de los países miembro. Eso ha permitido que las mujeres amplíen su margen de maniobra para actuar en instituciones públicas y, principalmente en localidades devastadas por conflictos armados, puedan formar parte de los contingentes de la ONU para la resolución de conflictos. De esa forma, muchas operaciones de paz han implementado secciones de género para tratar asuntos como la violencia sexual y de género. No obstante, vale destacar que muchas de esas secciones no emplean de modo adecuado los enfoques de género promovidos por la ONU, sino que equiparan género a un asunto único de mujeres (Drumond, 2010; Orta y Alaminos, 202I; Rebelo, 20I2).

En el caso ecuatoriano, como han defendido diversas autoras, los cambios políticos encaminados a partir de los planes de gobierno del periodo 2007-2017, y guiados por la cosmovisión indígena del Buen Vivir, han permitido el anclaje de las políticas de género en un sentido casi integral (Iturralde, 20I5; Radcliffe, 2017; Zaldumbide, 2020). Sin embargo, lo que respecta a las fuerzas armadas, dichas políticas han sido militarizadas (Zaragocín, 2018, p. 436). Esa militarización, vale recordar, actúa como elemento de contención del potencial de cambio de las políticas públicas emprendidas para alcanzar el Buen Vivir. Así, las instituciones militares permiten el ingreso cuantitativo de mujeres, pero niegan y limitan cualquier medida transformadora del componente de masculinidad que constituye el ethos militar.

En ese sentido, las medidas de equidad de género en los cuarteles se enfrentan a la masculinidad militarizada, la cual sirve como elemento regulador de las relaciones sociales. Katherine Herrera evidencia el efecto limitante de esas masculinidades al analizar cómo las mujeres son impedidas de participar en los cuerpos especiales de las fuerzas armadas. La autora destaca que los estigmas sociales que giran alrededor de la figura de la mujer actúan como una barrera para la aprobación de una serie de requisitos para ingresar en los cuerpos especiales. La

\footnotetext{
Un ejemplo de esto puede ser identificado en la polémica causada por el Ministerio de Defensa de Ucrania, en julio de 202I, cuando divulgó fotos de mujeres desfilando con tacones, como parte del ensayo para la conmemoración de los treinta años de independencia, que ocurriría el 24 de agosto (Redacción, 202I).
} 
autora ilustra la experiencia de las mujeres con el caso de la capitana Paola Barros, quien postuló al curso de comando y como respuesta obtuvo un: “icómo una mujer va a postular a un curso de comando"? (Herrera, 2020, p. II4). Es decir, el simple hecho de ser mujer constituye en sí un impedimento para su participación.

\section{Género y análisis del discurso: una alianza necesaria}

Con la finalidad de comprobar si la militarización de la equidad de género en el Ecuador produce nuevas formas de manifestaciones — rupturas, actualizaciones o cambios- de las masculinidades militarizadas en los documentos de defensa, en esta sección se presenta el dispositivo de análisis para examinar los documentos: Libro Blanco de Defensa $(2002,2006)$, la Agenda Política de Defensa (2009-20I3 y 20I4-20I7), la Política de Género de las Fuerzas Armadas del Ecuador (2013) y la Cartilla de Género Fuerzas Armadas del Ecuador (2017).

El dispositivo está compuesto por el corpus — desarrollado a partir de los documentos-y por la finalidad: localizar las manifestaciones de las masculinidades militarizadas en dicho corpus. Por discurso debe entenderse la "palabra en movimiento", cuyo propósito es la producción de efectos de sentido (Orlandi, 20 I2, p. I5). El discurso está representado por la palabra oral, escrita y por símbolos que se encuentran disputando significados en el campo subjetivo e ideológico (Brandão, 2012, p. 9). Para este estudio, los textos que forman el corpus son considerados discursos en sí. Se alía al dispositivo el análisis feminista postestructuralista, sugerido por Laura Shepherd, el cual permite complementar el estudio con un análisis de género feminista. La unión de esas dos metodologías permite localizar las formas en las cuales el género se manifiesta como elemento de poder en los discursos del corpus. La autora destaca su utilidad en la medida en que cuestiona el papel del lenguaje y del discurso en la emisión de políticas, preguntando principalmente cómo los textos significan (Shepherd, 2010, p. 3). Así, se parte del principio de que los discursos no son transparentes ni inertes (Orlandi, 20I2, pp. 15-16), sino dinámicos y contingentes.

En vista de que el trabajo se direcciona al análisis de las políticas de defensa, se debe entender que el lenguaje, como elemento de mediación entre los individuos y las realidades sociales y naturales que vivencian, constituye un vehículo de manifestación de la política (Shepherd, 2010 , p. 2). Es precisamente a partir del lenguaje, como máscara y escudo, que ciertas conductas han sido legitimadas. Eso, evidentemente, también ocurre con narrativas que se alimentan de esencialismos fundados en las asimetrías y relaciones de poder fundadas en entendimientos limitados sobre género. Algunas autoras que han estado en contacto con personal militar en el Ecuador, en espacios informales de los cuarteles, afirman que se escucha con frecuencia "bromas inocentes con dosis de machismo" (Zaldumbide, 2020, p. 72). Estas actitudes no están restrictas a meros comentarios, sino que influye directamente en que, a las mujeres militares, bajo el uso machista del lenguaje, se les atribuye tareas administrativas como parte de su aparente condición de mujer (Herrera, 2020, p. I 3 I). Se piensa, inclusive, que las políticas de género son direccionadas para beneficiarlas por sobre sus colegas hombres (Zaragocín, 2018, p. 44I). Es, por lo tanto, necesario "entender una política antes de ponerla en práctica" (Shepherd, 20 I0, p. 3), lo mismo se aplica al proceso de reformulación de dichas políticas. 
Tabla I. Categorías para el Análisis del Discurso

\begin{tabular}{|l|l|l|}
\hline Categorías & Definición & Componentes \\
\hline Ethos & Imagen de sí & Militares: hombres y mujeres \\
\hline $\begin{array}{l}\text { Condiciones } \\
\text { sociales } \\
\text { producción }\end{array}$ & $\begin{array}{l}\text { Contexto espacio temporal en que } \\
\text { se producen los discursos }\end{array}$ & $\begin{array}{l}\text { Contexto presidencial de Rafael } \\
\text { Correa (2007-20 I7): Constitución de } \\
2008 \text { y Buen Vivir }\end{array}$ \\
\hline Interdiscurso & $\begin{array}{l}\text { Discurso anterior que sustenta una } \\
\text { formación discursiva }\end{array}$ & $\begin{array}{l}\text { Narrativa del soldado griego como } \\
\text { guerrero mítico }\end{array}$ \\
\hline $\begin{array}{l}\text { Formación } \\
\text { discursiva }\end{array}$ & $\begin{array}{l}\text { Discursos vinculados a un enunciado } \\
\text { concreto }\end{array}$ & $\begin{array}{l}\text { Discurso de protector/mujer víctima } \\
\text { vulnerable y débil }\end{array}$ \\
\hline $\begin{array}{l}\text { Formación } \\
\text { ideológica }\end{array}$ & $\begin{array}{l}\text { Visión de mundo asociada a la } \\
\text { formación discursiva }\end{array}$ & $\begin{array}{l}\text { Visión de institución militar } \\
\text { masculina, tipo puro de guerreros } \\
\text { míticos }\end{array}$ \\
\hline
\end{tabular}

Fuente: Brandão, 2012; Maingueneau, 2015; Orlandi, 2012 (Elaboración propia)

El dispositivo analítico considera la Tabla I como punto de partida para identificar en los documentos las categorías constituyentes de la exploración del texto. El dispositivo muestra una visión parcial y predeterminada del campo discursivo (lenguaje) predominante en los documentos. En función de esa estructura, el objetivo es analizar las manifestaciones de las masculinidades militarizadas presentes en las disputas de sentido basadas en las categorías de género (masculino/ femenino). El procedimiento de manipulación de los documentos ocurre mediante la atribución de códigos - servicio militar, categoría mujer, concepción de género- para identificar las relaciones con las categorías presentes en la Tabla I. Por ejemplo, se buscará relaciones entre los códigos mujer y código servicio militar; o entre el código mujer y el código género. Eso permite tener una imagen de la formación discursiva para interpretar el sentido dado en el texto a los códigos y verificar las reproducciones, actualizaciones o rupturas por las cuales se manifiestan las masculinidades militarizadas.

Vale notar que, conceptualmente, la formación discursiva es un segmento interdiscursivo que permite, al invocar a la formación ideológica, decir algo. Por interdiscurso debe entenderse una acción de memoria y acumulación de sentidos formados históricamente. Así, el analista tiene como propósito identificar en los enunciados de la formación discursiva los sentidos preexistentes que se encuentran contenidos en dichos enunciados (Orlandi, 2012, pp. 42-43). Por ejemplo, considerando la cosmovisión indígena andina del Sumak Kawsay, el significante tierra, como Madre Tierra (Pachamama), no es el mismo otorgado a partir de una matriz de pensamiento occidental moderna. Otro ejemplo puede ser la herencia de entendimientos limitados sobre género, los cuales invocan al término como un asunto de mujeres. Es decir, esa formación discursiva puede ser vista como alineada a una interpretación masculinizada del término género, mediante la cual se presenta lo masculino como el orden natural y neutral de las cosas. En ese sentido, el análisis del discurso permite visualizar las condiciones sociales que propician ciertos discursos y a qué sentidos 
se vinculan, siendo posible que las enunciaciones presenten regularidades o transformaciones que permiten cuestionar cómo esos discursos significan (Shepherd, 2010, p. 3).

\section{Política de defensa ecuatoriana: metamorfosis de las masculinidades militarizadas}

"Nosotros desarrollamos estas políticas de género basadas en las ideas de la Revolución Ciudadana de igualdad y el énfasis en el Buen Vivir y la equidad de género. Vimos la oportunidad: ¡ahora o nunca! Sabíamos que iba a incomodar, pero teníamos el aval político para hacerlo. Por supuesto, los oficiales militares de alto nivel, como el comando conjunto, tendrían que aprobarlo, pero teníamos nuestros aliados y funcionó" (Zaragocín, 2018, p. 439).

Los planes de gobierno del periodo correísta contenían la semilla para la promoción de la interculturalidad y la equidad de género, principalmente los planes del Buen Vivir redactados posteriormente a la Constitución de 2008. El Buen Vivir es definido como proceso de "reivindicaciones por la igualdad y la justicia social, y desde el reconocimiento, la valoración del diálogo de los pueblos y de sus culturas, saberes y modos de vida” (Ecuador, 2009, p. 10). Bajo ese escenario, las políticas de defensa fueron emitidas con un enfoque inclusivo. Entre 2007 y 2014 , el Ecuador tuvo un total de tres ministras de la defensa: Guadalupe Larriva González (2007), Lorena Escudero Durán (febrero a agosto de 2007) y María Fernanda Espinosa (noviembre de 2012 a septiembre de 2014). Escudero fue la responsable por implementar reformas en las mallas curriculares de las instituciones de formación militar para introducir temas de género (Herrera, 2020, p. I03). Por su parte, en la gestión de Espinosa se emitió el documento Política de Género de las Fuerzas Armadas del Ecuador, en 2013. La presencia de tres mujeres en un espacio de liderazgo comúnmente ocupado por hombres, usualmente hombres militares, constituye un punto de inflexión en términos simbólicos. Esa presencia ayuda a resignificar el papel de la mujer en la política, como corrobora el testimonio de una funcionaria del Ministerio de la Defensa, citado al inicio de este apartado.

A partir del análisis de los documentos de defensa, la presente subsección muestra tres categorías por las cuales se pueden identificar las metamorfosis discursivas de las masculinidades militarizadas como respuesta a las políticas de género. A continuación, se presentan las relaciones establecidas entre los códigos seleccionados para el análisis del discurso que permitieron formular las categorías propuestas. Se recuerda que los códigos son: mujer, concepción de género y servicio militar.

\section{I. La ciudadana parcial y no autorizada: Libro Blanco de Defensa}

Los Libros Blancos de Defensa, como argumenta Julián González Guyer, llegaron en el marco del fin de la Guerra Fría para fomentar la confianza entre los países de América Latina (Guyer, 2017, Pp. 17-18). En el caso ecuatoriano, el primer documento data del año 2002, seguido por uno de 2006. En ellos, la figura de la mujer ha estado marcada por una inclusión restricta, principalmente 
al tratarse de las labores más asociadas a la defensa, como lo es el uso de armas. En otras palabras, el simbolismo de las mujeres denota la ausencia casi completa de la mujer en las tareas de la defensa nacional, ya que los códigos mujer y código género se caracterizan por su ausencia en el campo discursivo. Vale destacar que por discurso no se entiende únicamente la palabra escrita, sino que también se contempla la presencia de ilustraciones que señalen formas de representación. Así, es importante mencionar que el documento utiliza imágenes de hombres para ilustrar actividades relacionadas al uso de armas, preparación física y entrenamiento militar. Sin embargo, como apunta Herrera (2020, p. I 16), esas representaciones proyectan solamente una parte de la formación militar, omitiéndose las actividades y recursos primordiales como la inteligencia, la resistencia psicológica, la parte de fundamentos técnicos, la referente a la táctica en la estrategia y los fundamentos teóricos.

La actividad física constituye apenas una parte de la preparación militar. No obstante, es la que mayor centralidad ha ganado, principalmente entre los hombres, "ya que se sienten mejor preparados y adaptados que ellas en lo físico, sin importarles que el resto del entrenamiento sea igual de transcendente" (p. II6). A partir de esas evidencias se puede identificar el efecto de la penetración de las masculinidades militarizadas en la representación del papel del hombre militar ecuatoriano.Así, la ausencia de la mujer constituye una forma de discurso, anteponiendo el silencio a su presencia y manifestando su simbolismo como un elemento indeseado en la esfera castrense. El código género aparece una única vez, alineado a la integración nacional como parte de los objetivos e intereses nacionales de la política de defensa.

Por su parte, el código servicio militar, en el documento de 2002, muestra su carácter de obligatoriedad, pero omite la identificación sexual de quién puede realizarlo. En aquel momento, el servicio militar era una tarea exclusiva de los hombres. Además, el código muestra un vínculo directo con las nociones de ciudadanía, defensa y es considerado un "factor de orgullo e identidad nacional” (Ecuador, 2002, Pp. II9-123). En otras palabras, el sentido de ciudadano guerrero, presente en el imaginario social de la construcción de la guerra como una actividad de hombres (Grant, 1992, p. 83; Sylvester, 2015, p. 587), encuentra su reflejo en las fuerzas armadas y en la sociedad ecuatoriana (Iturralde, 20I5, p. 34).

El Libro de 2006 muestra un tímido alineamiento con normativas internacionales como la Declaración del Milenio, del 2000. El código mujer emerge como una mera formalidad: la "presencia de la mujer fortalece el talento humano de la institución y demuestra el grado de transformación en el que se halla inmersa la defensa nacional" (Ecuador, 2006, p. 88). Sin embargo, no se explica en qué sentido su presencia es positiva, ni que transformación aporta.

Algunos elementos emergen al contrastar con la Tabla I. En primer lugar, el ethos militar se vincula exclusivamente a la figura del hombre, considerando la guerra y la protección del estado como su función social. Esta proyección es reforzada por el conflicto con el Perú, de 1995, aludiendo al triunfo militar ecuatoriano. El interdiscurso dominante del guerrero mítico sustenta la figura del militar ecuatoriano y permite la formación discursiva del ciudadano patriota, aquel que realiza el servicio militar y es autorizado para emprender tareas de defensa nacional, constituyendo un factor de orgullo. La formación ideológica (visión de mundo) indica la ausencia de las mujeres, como ciudadanas incompletas y vulnerables, y está vinculada a la construcción de la 
guerra como un ejercicio masculino (Enloe, 20I4; Kronsell, 20I2;Tickner, 1997).Así, se considera que la mujer, en los documentos, ocupa el lugar de la no autorizada y de la ciudadana parcial, pues, aunque reconocida, no es contemplada como revestida del ethos militar masculino.

\subsection{La ciudadana autorizada:Agenda Política de la Defensa Nacional}

Las agendas políticas trajeron importantes cambios en materia de inclusión social y modificaron las nociones tradicionales del concepto de seguridad. Se inauguró, así, el paradigma de la seguridad integral para promover "la paz, los derechos humanos y el Buen Vivir, en lo atinente a la defensa" (Ecuador, 20I I, p. I2). La agenda muestra un enfoque multidimensional, afiliado al concepto de seguridad humana, el cual promueve una mirada desde la seguridad hacia el individuo, sin otorgar la máxima centralidad al estado (ONU PNUD, 1994, p. 25).

El código género, en la agenda de $20 \mathrm{I}$ I, incluye hombres y mujeres. La agenda es propositiva al recomendar la elaboración de un "diagnóstico de género de Fuerzas Armadas" tanto cualitativo como cuantitativo (Ecuador, 20II, p. 27). El código también está asociado a la necesidad de "respetar, proteger y garantizar los derechos humanos de todas las personas, independientemente de su sexo, etnia, edad, identidad de género, condición socioeconómica, condición migratoria, orientación sexual, discapacidad u otra distinción" (p. 47). Se evidencia en la agenda una mayor presencia de cuestiones relacionadas a una perspectiva interseccional.

En ese sentido, como indica Sofía Zaragocín, vale mencionar que la intersección de elementos étnico/raciales, de clase y de género es parte de la propuesta formal de inclusión social, originada en la idea de refundación del estado plurinacional e intercultural a partir de 2008 (Walsh, 2015, p. 20). Sin embargo, ello no implica necesariamente que exista un proceso directo de implementación de políticas públicas con efectos visibles a corto plazo. Es precisamente ese punto que Zaragocín destaca al mencionar que la interseccionalidad de la propuesta de inclusión ha sido militarizada, puesto que ha perdido su potencial de transformación social (Zaragocín, 2018, p. 436). Los efectos de esa militarización son observados en la ausencia de indicadores y bases de datos que permitan diferenciar la población de hombres y mujeres en las fuerzas armadas por recortes étnico raciales, teniendo como consecuencia la falta de datos para la implementación y (re)formulación de políticas más cercanas a la realidad de la población ecuatoriana.

En cuanto al código servicio militar, la terminología sufre una alteración para servicio cívico militar voluntario ${ }^{7}$. Pese al cambio, la política continuaba direccionada únicamente hacia los hombres. Apenas en 2018, el llamado al servicio cívico militar voluntario será realizado hacia las mujeres, considerando ciento noventa y nueve cupos (El Comercio, 20I8). De cierta forma, el carácter voluntario del servicio permite desvincular las figuras del ciudadano y del guerrero, abriendo la posibilidad para superar los moldes del guerrero mítico (Tickner, 1992, p. 28) que fueron reforzados por el conflicto armado con el Perú. Así, se abre un pequeño margen para que la mujer ecuatoriana reivindique su lugar como ciudadana y como agente capaz de ejercer la defensa nacional.

\footnotetext{
La Ley de Servicio Militar Obligatorio en Fuerzas Armadas Nacionales, suscrita en 1994 y modificada en 2007, contempla que las mujeres
} serán incluidas siempre y cuando sea necesidad de la defensa nacional. 
La agenda del 20I4, en cierta medida, representa la consolidación de los términos formales de la equidad de género para la política de la defensa. Eso se puede verificar en la sección IV del documento Principios rectores de la Defensa, en la cual se incorporan conceptos importantes como cultura de paz, enfoques de igualdad, equidad de género, interculturalidad.Asimismo, la sección VII -EjeTransversal- muestra una subsección de género alineada a los principios de no discriminación de la CEDAW, de 1979. El documento también cita datos de las mujeres en las diferentes fuerzas y anuncia la "posibilidad de acceder a los altos grados" (p. 4I). El incremento de las mujeres en las fuerzas armadas corresponde a I,69\% (20I2); 2,60\% (20I4); 2,90\% (20I6) (Donadio, 20 I6, p. I 53). No obstante, el acceso de las mujeres está condicionado a tres escalones de la jerarquía militar (subteniente, teniente, capitán), encontrándose limitadas a los grados inferiores $y$, en muchas ocasiones, reproduciendo trabajos que son un espejo de las labores domésticas que muchas de ellas desempeñan en sus hogares (Chacón, 2014, p. 49; Herrera, 2020, p. 127). Se puede evidenciar nuevamente los efectos de las masculinidades militarizadas que actúan como mecanismo de restricción permanente (Tapscott, 2020), imponiendo formas de participación que reproducen las actividades del espacio doméstico.

Contrastando con la Tabla I, se observa un alejamiento del ethos militar de una concepción estrictamente fundamentada en el heroísmo. El interdiscurso del guerrero mítico sufre una invasión por parte de la presencia de la mujer que también posee la capacidad de ejercer tareas de defensa nacional. La formación ideológica, influenciada por los lineamientos del Buen Vivir, indica un campo favorable para la equidad de género, aunque muchas perspectivas esencialistas sean reproducidas (mujer vinculada a trabajos administrativos y de cuidado). Así, las mujeres en las agendas emergen bajo la representación de ciudadanas autorizadas, indicando que las políticas de género, hasta cierto punto, han ampliado sus posibilidades de participación y han iniciado un proceso de contestación de la organización social impuesta por las masculinidades militarizadas. En efecto, las políticas de género muestran su relevancia para la transformación discursiva en lo que respecta a la inclusión de las mujeres en los espacios militares.

\subsection{La mujer militar: Política de Género de las Fuerzas Armadas del Ecuador y Cartilla de Género Fuerzas Armadas}

El primer documento, expedido en 2013 bajo el comando de María Fernanda Espinosa, está direccionado a mejorar "la integración de la mujer en la institución militar, garantizando la igualdad de derechos y oportunidades entre hombres y mujeres” (Ecuador, 20I3, p. 8). Consta de cuatro objetivos: I) fortalecer la igualdad de oportunidades para hombres y mujeres; 2) fomentar el buen vivir entre el personal masculino y femenino; 3) fomentar la coeducación con base en principios de igualdad y no discriminación por género; 4) control y prevención de la discriminación por género.

De forma general, el texto se encuentra elaborado de modo a contemplar tanto al hombre y a la mujer como partes constituyentes del código género. Esto viene al encuentro de medidas exhortadas desde espacios multilaterales como la ya mencionada Resolución 1325/2000 de la ONU (Carreiras, 2018, p. 132). Al tratar de asuntos como violencia de género, intrafamiliar, acoso sexual o laboral y discriminación, el documento omite cualquier vinculación binaria que proyecte la figura del hombre como perpetrador de violencia y de la mujer como víctima. Por el contrario, 
incentiva la corresponsabilidad en asuntos como maternidad y paternidad. El uso adecuado de conceptos, como el de género, constituye un avance significativo al no caer en el espacio común de igualar género a un asunto de mujeres (Solhjell, 2014, p. 100). Discursivamente, como indicaría Laura Shepherd, el efecto del uso correcto del lenguaje permite la "aplicación de políticas de un modo productivo y potencialmente transformador" (Shepherd, 2010, p. 4). No obstante, debe considerarse que el uso del término género en el documento reproduce una lógica binaria y excluyente, puesto que no contempla la presencia de personas de las comunidades ${ }^{8}$ LGBTQIA+.

Se observan rupturas importantes con relación a las formaciones discursivas e ideológicas imperantes en los Libros Blancos de 2002 y 2006. En primer lugar, en las agendas políticas se abre un espacio para la representación de las mujeres, condición casi de absoluta ausencia en los Libros Blancos. En estos últimos, además, se produce un efecto de silenciamiento debido a la omisión de términos como mujer y género, con lo cual se refuerza el ideal de masculinidad militarizada (imagen del guerrero mítico) inherente al campo y al ethos castrense (Tickner, 1992, p. 28). Eso conlleva a impedir el ingreso de mujeres en las fuerzas armadas y es visible cuando la política de género de 2013 indica la necesidad de "generar cambios en la legislación militar con enfoque de género" (Ecuador, 20 I3, p. I4), buscando “medidas de acción afirmativa para ampliar y fortalecer la participación de la mujer en las Fuerzas Armadas" (p. I4). Los índices de participación de mujeres evidencian el problema, pues constituyen aproximadamente el 3,5\% del personal total de las Fuerzas Armadas (Zaldumbide, 2020, p. 6I).

En segundo lugar, la idea de corresponsabilidad en el cuidado de los hijos anuncia una fractura en la noción binaria entre público y privado, lo cual ayuda a repensar el trabajo doméstico 9 y de cuidados no más como carga únicamente femenina. Las políticas buscan también la integración plena de las mujeres de modo progresivo en todos los ámbitos. El acceso a armas de combate es quizá el principal impedimento, siendo relegadas a tareas de apoyo, administrativas, logísticas o de cuidado (Herrera, 2020, p. I I0; Iturralde, 20 I 5, p. 33; Morales et al., 20 I7, p. I26). En pocas palabras, el documento presenta alternativas relevantes en materia de integración de las mujeres, aunque persiste la falla en implementar una perspectiva inclusiva en términos étnico raciales, problema heredado del proceso de militarización de las perspectivas interseccionales, tal y como argumenta Zaragocín (2018, p. 440).

La cartilla de género de 2017 es un manual con referencias legales internas e internacionales, relacionadas a temas de género para la "promoción de los derechos humanos y género, para coadyuvar a garantizar el proceso de inclusión del personal militar femenino" (Ecuador, 2017, p. 8). Para tal efecto posee tres ejes: I) glosario de preguntas frecuentes sobre derechos humanos $y$ género; 2) legislación internacional y nacional; 3) legislación militar.

Sobre la legislación militar, asunto al cual se dará mayor relevancia, el texto muestra el

8 El Ecuador y la región latinoamericana están lejos de romper las barreras de los estigmas sociales impuestos a las comunidades LGBTQIA+. Datos sobre violencia hacia esas comunidades apuntan que aproximadamente 3.500 personas fueron asesinadas en América Latina y el Caribe entre 2014 y 2020. Muchos de esos crímenes son cometidos por preconcepto contra la identidad de género y orientación sexual de las víctimas (Palomino, 202I).

9 Ecuador posee alta desproporción entre trabajo remunerado y no remunerado para hombres y mujeres. Según la CEPAL, corresponde a: hombres (cuarenta y cuatro horas semanales remuneradas y 9,9 no remuneradas); mujeres $(20,7$ horas remuneradas y treinta y siete no remuneradas), indicando la sobrecarga de trabajo doméstico en las mujeres (OIG CEPAL, 202I). 
andamiaje legal sobre la igualdad de género; pero, esa sección específica muestra al código género asociado únicamente hacia las mujeres y sus necesidades. Algunos puntos marcantes son la concesión de licencia por maternidad por un total de doce semanas, omitiendo cualquier tipo de licencia por paternidad y distanciando la noción de corresponsabilidad incentivada en la política de 2013. Es decir, el código género, que en la política de 2013 era entendido como un amparo hacia hombres y mujeres, pierde su potencial transformador al ser visto como un asunto únicamente de mujeres. Ese movimiento de retroceso es común a lo que Helena Carreiras determina como ciclos de expansión y retracción. Es decir, las políticas siempre pueden ser revertidas o se pueden reinstalar medidas restrictivas (Carreiras, 2018, p. I34).

El asunto de la infraestructura militar constituye también un elemento central, siendo previsto que las "unidades o repartos militares para alojar al personal militar femenino, deberán prever habitabilidad que brinde seguridad y privacidad" (Ecuador, 2017, p. 63). Sobre la "cortesía militar", el texto exhorta al personal masculino y femenino a mantenerse siempre dentro de las normas, "sin que prevalezca la condición de mujer" (p. 50). El trecho es interesante dado que la cortesía forma parte del ethos militar, indicando jerarquías, además de ser una expresión de la rigidez disciplinaria, propia del militarismo (Via, 20I0, p. 44). La observación direccionada a la "condición de mujer" viene al encuentro de la formación discursiva del hombre como categoría universal. Otro ejemplo es visible en el uso del término "mujer militar" y no "la militar", esto indica resistencias simbólicas a la presencia de la mujer y las muestra como sujetos ajenos al territorio castrense.Así, como mencionado en la sección teórica, pese al cumplimiento de los padrones, ellas siempre serán vistas como invasoras o amenaza al territorio militar masculino, como lo evidencia el testimonio a seguir:

"Los hombres todavía no están de acuerdo con que estemos aquí. Nada ha cambiado. Todavía debo demostrar mi valía dos o tres veces más que mis homólogos masculinos. Además, ahora con las políticas de género, los hombres están aún más furiosos con nosotras porque dicen que ahora tenemos protección extra. Dicen que [mujeres y hombres] deben ser tratados por igual y que nosotras [las mujeres] no debemos tener prioridad" (Zaragocín, 2018, p. 44I).

Es visible que la cartilla es una respuesta legal a la creciente presencia de las mujeres en las fuerzas armadas, producto de las demandas internacionales y sociopolíticas sobre el reconocimiento e importancia de su papel en la sociedad.Además, como muestra Carreiras, las propias instituciones se encuentran sometidas a nuevas dinámicas operativas y técnicas, dependiendo cada vez más de profesionales especializados, lo cual también ha implicado el ingreso de mujeres (Carreiras, 20 I8, p. 132). Sin duda, cuestiones como la cortesía militar, la licencia maternidad o una propicia condición de habitabilidad no serían abordadas si no fuese por el creciente ingreso de mujeres, lo cual desafía constantemente los ideales de la masculinidad militarizada. Pese a ello, como destaca Katherine Herrera, las demandas de la masculinidad militarizada continúan suprimiendo el potencial de acción de las mujeres al persistir limitantes relacionadas principalmente a su acondicionamiento físico (Herrera, 2020, pp. I I6-I I8). Así, se considera que las mujeres están confinadas a ocupar el espacio de la mujer militar, un otro cuya presencia en el campo castrense se espera que sea pasajera. 


\subsection{Las resistentes murallas de las masculinidades militarizadas}

Como resultado del dispositivo analítico aplicado al análisis de los documentos, la Tabla 2 tiene la finalidad de ilustrar las alteraciones de las categorías que constituyen el conjunto del análisis postestructuralista y el análisis del discurso para los documentos de defensa. Así, se pueden identificar las variaciones del ethos militar, las condiciones sociales de producción, los interdiscursos, las formaciones discursivas, las formaciones ideológicas y, finalmente, las metamorfosis de las masculinidades militarizadas.

Tabla 2. Comparativo analítico de los documentos de defensa.

\begin{tabular}{|c|c|c|c|}
\hline Categorías & $\begin{array}{l}\text { Libros Blancos } \\
(2002 \text { y 2006) }\end{array}$ & $\begin{array}{l}\text { Agendas Políticas } \\
(201 \text { I y 2014) }\end{array}$ & $\begin{array}{l}\text { Políticas de género } \\
(2013 \text { y } 2017)\end{array}$ \\
\hline Ethos & $\begin{array}{l}\text { Militar hombre como } \\
\text { ciudadano guerrero. } \\
\text { Servicio militar } \\
\text { obligatorio }\end{array}$ & $\begin{array}{l}\text { Fractura militar } \\
\text { hombre guerrero, } \\
\text { inclusión "ciudadana } \\
\text { autorizada". Servicio } \\
\text { militar facultativo }\end{array}$ & $\begin{array}{l}\text { Formalización de la } \\
\text { fractura del militar } \\
\text { hombre. } \\
\text { Inclusión "mujer } \\
\text { militar". } \\
\text { Servicio militar } \\
\text { facultativo }\end{array}$ \\
\hline $\begin{array}{l}\text { Condiciones } \\
\text { sociales } \\
\text { producción }\end{array}$ & $\begin{array}{l}\text { Gesta del Cenepa } \\
\text { 1995- 1998; heroísmo } \\
\text { militar }\end{array}$ & $\begin{array}{l}\text { Contexto Rafael } \\
\text { Correa (2007-2017): } \\
\text { Constitución de } 2008 \text { y } \\
\text { Buen Vivir }\end{array}$ & $\begin{array}{l}\text { Contexto Rafael } \\
\text { Correa (2007-2017): } \\
\text { Constitución de 2008 } \\
\text { y Buen Vivir }\end{array}$ \\
\hline Interdiscurso & $\begin{array}{l}\text { Narrativa del soldado } \\
\text { griego y guerrero } \\
\text { mítico }\end{array}$ & $\begin{array}{l}\text { Narrativa de inclusión } \\
\text { social bajo el Buen Vivir }\end{array}$ & $\begin{array}{l}\text { Narrativa de inclusión } \\
\text { de la mujer en el } \\
\text { espacio militar }\end{array}$ \\
\hline $\begin{array}{l}\text { Formación } \\
\text { discursiva }\end{array}$ & $\begin{array}{l}\text { Discurso de } \\
\text { protector/mujer } \\
\text { víctima vulnerable y } \\
\text { débil }\end{array}$ & $\begin{array}{l}\text { Inclusión discurso } \\
\text { sobre género. } \\
\text { Hombre y mujer } \\
\text { ejecutores de la } \\
\text { defensa nacional }\end{array}$ & $\begin{array}{l}\text { Discurso de género } \\
\text { inclusivo (hombres y } \\
\text { mujeres). } \\
\text { Desliz esencialista: } \\
\text { género = mujer }\end{array}$ \\
\hline $\begin{array}{l}\text { Formación } \\
\text { ideológica }\end{array}$ & $\begin{array}{l}\text { Visión de mundo } \\
\text { militar y masculina } \\
\text { como tipo puro: } \\
\text { guerreros míticos }\end{array}$ & $\begin{array}{l}\text { Visión de mundo } \\
\text { anclada al Buen Vivir, } \\
\text { equidad de género }\end{array}$ & $\begin{array}{l}\text { Visión de mundo } \\
\text { anclada al Buen Vivir, } \\
\text { equidad de género }\end{array}$ \\
\hline $\begin{array}{l}\text { Metamorfosis } \\
\text { Masculinidades } \\
\text { militarizadas }\end{array}$ & $\begin{array}{l}\text { Mujer como } \\
\text { "ciudadana no } \\
\text { autorizada" }\end{array}$ & $\begin{array}{l}\text { Mujer como "ciudadana } \\
\text { autorizada" }\end{array}$ & $\begin{array}{l}\text { Mujer como “otro”, la } \\
\text { "mujer militar" }\end{array}$ \\
\hline
\end{tabular}

Fuente: Elaboración propia.

La tabla permite visualizar que el contexto de formulación de la Política de Género (20I3) 
y de las Agendas Políticas (20l I-20l4) constituye el ápice de la promoción de las políticas de igualdad de género en las Fuerzas Armadas. Los Libros Blancos $(2002,2006)$ muestran un panorama anclado a una noción de heró́smo masculino vinculado a la experiencia del conflicto del Cenepa, de 1995, con el Perú. Los documentos posteriores superan, hasta cierto punto, esa narrativa. Sin embargo, ante el crecimiento de las políticas direccionadas hacia la inserción de las mujeres en los cuarteles, entre el periodo 20l I-20l4, los discursos presentes en los documentos posteriores, principalmente en la Cartilla de Género (2017), muestran la existencia de resistencias hacia la inclusión integral del género. Al reducirse el término género a un asunto de mujeres, su potencial de cambio es contenido, impidiendo que ocupe un lugar central en el proceso transformativo de las relaciones sociales en los cuarteles, objetivo que la política de 2013 pretende cumplir. Esta lógica continúa legitimando la exclusión de las mujeres en diversos espacios de poder en las instituciones militares, principalmente en aquellas que desafían la corporificación de la hipermasculinidad, ya que únicamente los hombres serían capaces de alinearse a las demandas físicas impuestas por la generificación de la guerra (Cockburn, 2013, p. 434; Hooper, 1999, p. 480).

Es importante destacar a la política de 2013 como un punto de partida relevante para las políticas de género. Pese a los ciclos de expansión y retracción de esas medidas de transformación social e institucional, la presencia formal es un indicador relevante de cambio. En ese sentido, se puede argumentar que las políticas de género desempeñan un papel relevante de contención del avance de las masculinidades militarizadas, aunque dichas masculinidades muestren su capacidad de adaptación para limitar la presencia de las mujeres.

Evidentemente, las medidas transformativas no habrían ocurrido de no presentarse las condiciones sociales de producción adecuadas para la penetración discursiva de la inclusión social amparada por la ideología del Buen Vivir (Walsh, 20I5, p. 2I). Esa cosmovisión indígena dio el amparo para el ingreso de la curiosidad feminista (Enloe, 20I4, p. 8) en el pensamiento ecuatoriano guiado por un norte feminista decolonial del Buen Vivir (Zaragocín, 2017, p. 439). No obstante, las disputas discursivas, entre la inclusión de la igualdad de género y el discurso del ethos militar dominante masculino y militarizado, son parte del desafío para que la igualdad de género ocupe el espectro cultural de las instituciones militares y sociales en el país. El mismo desafío ha sido colocado ante la academia ecuatoriana para que actúe como vehículo de propuestas transformativas y para que lance luz hacia las necesidades sociales propias de un país diverso y plurinacional como lo es el Ecuador.

\section{Conclusiones}

La elección presidencial de Rafael Correa se produjo en un contexto internacional y regional que permitió el establecimiento de nuevas formas de repensar tanto la política internacional como interna. Las políticas de defensa, como objeto de estudio del presente trabajo, muestran cambios no apenas en términos de inclusión social, sino también con relación a la inauguración de nuevos paradigmas de defensa alejados de visiones tradicionales, como es la noción de seguridad integral.

La inclusión de mujeres en espacios políticos comúnmente ocupados por hombres militares, como el Ministerio de la Defensa, y la promoción de políticas de género para incentivar 
la participación femenina en las fuerzas armadas constituyen medidas innovadoras y desafiantes del campo y del ethos militar. Estas medidas fueron direccionadas a partir de la nueva Constitución de 2008 y de la inserción de la ideología del Buen Vivir, como puente para la inclusión social en un país autodenominado plurinacional.

Pese a la promoción de políticas de género en los cuarteles, se observa que la equidad de género ha sido militarizada, su potencial de transformación de las relaciones sociales ha sido sofocado. Este fenómeno de la militarización indica que el aumento numérico de mujeres no necesariamente modifica o altera la percepción interna que se tiene sobre su papel social. Además, a partir de la formulación de tres categorías, se visualiza que las mujeres ocupan un lugar subordinado, la posición de un otro indeseable y que constituye una amenaza para el ethos y el campo militar que ha predominado desde la formación del Estado ecuatoriano.

Ante ese panorama, el presente trabajo tuvo como objetivo localizar las metamorfosis experimentadas por las masculinidades militarizadas en las políticas de defensa, mediante el uso de una perspectiva feminista postestructuralista aliada al análisis del discurso de vertiente francesa. El corpus de análisis consistió en los documentos de defensa emitidos durante el mandato de Rafael Correa (2007-20I7). Vale recalcar que el dispositivo de análisis empleado no pretende dar respuestas definitivas o únicas. Por el contrario, al considerar el discurso como elemento dinámico y el dispositivo de análisis sujeto a reconfiguraciones, otros resultados pueden ser extraídos de la continuación de este estudio bajo la movilización de diferentes perspectivas teóricas. Sin embargo, se destaca que el análisis aquí realizado se inserta en un campo poco explorado en los estudios de seguridad internacional direccionados hacia la experiencia ecuatoriana. Se buscó, así, contribuir al entendimiento de las políticas públicas, desde el margen crítico feminista, emitidas en el país bajo el paraguas de la inserción de la mujer en las fuerzas armadas.

Los resultados del análisis son visibles en diversos puntos. El primero de ellos radica en el componente conceptual movilizado para realizar el análisis. Efectivamente, la masculinidad y el militarismo presentan un obstáculo permanente hacia las transformaciones que la presencia de mujeres puede generar en los espacios castrenses. El campo y el ethos militar están en permanente desafío debido a la emisión de las políticas de género y, consecuentemente, al inevitable ingreso de las mujeres. Eso genera reacciones de rechazo hacia la presencia femenina en los cuarteles, percibida como una amenaza a los principios fundacionales del ethos militar masculino.

Otro punto corresponde al marco legal. Los documentos de defensa reflejan un estado superior de inclusión, puesto que reafirman normativas internas de inclusión, bajo la bandera del Buen Vivir, e instrumentos legales internacionales. Sin embargo, el análisis muestra que el marco legal, aunque innovador, presenta resistencias, en su construcción discursiva, hacia el ingreso de la mujer. Esas resistencias no son explícitas, sino que reflejan el hermetismo del campo y del ethos militar masculino (ideal del guerrero mítico) y militarizado (guerrero disciplinado y apto para el uso de la fuerza). Así, en la medida en que la normativa legal militar se ve invadida por cuerpos ajenos, no masculinos ni militarizados, reacciona por medio de la construcción de un espacio reservado, no enteramente militar y permanentemente subordinado a los principios de la masculinidad militarizada. 
Es así, como tercer punto, que surgen las tres categorías propuestas como parte de este trabajo para identificar la presencia de las mujeres en los diferentes momentos de la formulación de la política de defensa del Ecuador. En primer lugar, los primeros documentos, Libros Blancos de 2002 y 2006, muestran la ausencia de las mujeres como agentes aptos para las funciones de la defensa nacional. Por el contrario, debido al reciente conflicto con el Perú, considerado un evento heroico de guerra y triunfo militar ecuatoriano, la conformación del ethos militar está fuertemente anclada al ciudadano guerrero, más aún bajo la obligatoriedad del servicio militar masculino. En ese espacio, la mujer emerge bajo la categoría de ciudadana parcial o no autorizada, debido a que es excluida de las tareas de defensa nacional.

Las agendas políticas de 201 I y 20 I4, por su parte, bajo las transformaciones del Buen Vivir, muestran modificaciones relevantes en materia de defensa. Por ejemplo, el servicio militar pasa a ser servicio civil militar voluntario, lo cual anuncia modificaciones en la construcción del ciudadano guerrero masculino. El ethos militar es forzado a ceder ante la presencia autorizada de mujeres, bajo el marco legal de las políticas de género. Sin embargo, la legislación militar, en la construcción de espacios alternativos para las mujeres, limita su participación a ciertos rangos y actividades que no comprenden el acceso a armas, sino que las restringe a espacios administrativos, logísticos y de cuidado.Aquí se evidencia que la masculinidad militarizada todavía encuentra formas de adaptarse y someter otro tipo de cuerpos que no necesariamente alcanzan las demandas de su tipo puro. Es entonces que las mujeres emergen como ciudadanas autorizadas, presentes en los cuarteles, pero limitadas a ciertas tareas que no afecten de manera profunda el ethos militar.

Por fin, las políticas de género emitidas en 2013 y 2017 son la reafirmación del andamiaje legal de inclusión de género en la política de defensa. Son instrumentos que buscan favorecer a la inclusión integral de la mujer en los cuarteles y alterar la legislación militar para beneficiar su inserción cuantitativa y cualitativa. El documento de 2013 , realizado durante la gestión de la ministra de defensa María Fernanda Espinosa, es innovador puesto que contempla una perspectiva amplia de género al incluir la presencia y necesidades de hombres y mujeres. No obstante, el documento de 2017, sofoca el potencial del anterior al igualar mujer a género. Así, la Cartilla de Género muestra, en su sección sobre legislación militar, que los asuntos de género continúan a ser percibidos como un asunto de mujeres. Pese a que la mujer ocupa un espacio de mayor visibilidad, el documento muestra, nuevamente, la capacidad de adaptación de la masculinidad militarizada. Se inaugura, entonces, el espacio de un otro, ajeno al verdadero campo y ethos militar, que es representado por la categoría de la mujer militar, un ser que habita en un oxímoron en el cual debe mostrarse el doble de masculina que sus colegas hombres para recibir menos de la mitad del reconocimiento como militar.

\section{Referencias}

Acosta, A. (2012). The Buen Vivir:An Opportunity to Imagine Another World. En Inside a Champion. An Analysis of the Brazilian Development Model (pp. I92-2I0). Heinrich Böll Foundation.

Acosta, A. y Cajas-Guijarro, J. (2018). Una década desperdiciada. Las sombras del correísmo. Centro Andino de Acción Popular-CAAP.

Aleksiévitch, S. (2016). A guerra não tem rosto de mulher. Companhia das Letras.

Amossy, R. (20II). Da noção retórica de ethos à análise do discurso. En Amossy, R. (Ed.). Imagens de Si no Discurso: a construção do ethos (pp. 9-23). Contexto.

Baaz, M.E. y Stern, M. (20I3). Fearless Fighters and Submissive Wives: Negotiating Identity among Women Soldiers in 
the Congo (DRC). Armed Forces and Society, 39 (4), 7 I I-739.

Basabe-Serrano, S. (20I3). Rafael Correa: el antes y el después de la política ecuatoriana. Iberoamericana, I 3 (50), I68173.

Beasley, C. (2008). Rethinking hegemonic masculinity in a globalizing world. Men and Masculinities, I I (I), 86-I03.

Blanco,J.P.y Aguiar, E.P.(2020). El Buen Vivir como discurso contrahegemónico. Postdesarrollo, indigenismo y naturaleza desde la visión andina. Mana, 26 (I)

Brandão, H.H. (20I2). Introdução à Análise do Discurso. Unicamp.

Carreiras, H. (2018). La integración de género en las Fuerzas Armadas Condicionamientos y perspectivas. Nueva Sociedad, 278

Chacón, R. (2014). Mujer militar: su inclusión en las Fuerzas Armadas. Ministerio de Defensa Nacional del Ecuador.

Cockburn, C. (20I3). War and security, women and gender: an overview of the issues. Gender \& Development, 2I (3), 433-452.

Connell, R. (2005). Masculinities. University of California Press.

Connell, R. (20I2). Masculinity research and global change. Masculinities and Social Change, I (I), 4-I8.

Connell, R.W. y Messerschmidt, J.W. (2005). Hegemonic Masculinity: Rethinking the Concept. Gender \& Society, 19 (6), 829-859.

Donadio, M. (2016). Atlas Comparativo de la Defensa en América Latina y Caribe. Red de Seguridad y Defensa de América Latina-RESDAL.

Drumond, P. (20I0).As Políticas de Gênero e as Operações de Paz : Uma Análise Crítica do Caso da MONUC. Revista Da Escola De Guerra Naval, I5, 79- 103

Ecuador. (2002). Libro Blanco de la Defensa Nacional. Ministerio de Defensa Nacional.

Ecuador. (2006). Libro Blanco de la Defensa Nacional. Ministerio de la Defensa.

Ecuador. (2008). Constitución del Ecuador 2008.

Ecuador. (2009). Plan Nacional para el Buen Vivir 2009-20 I 3: Construyendo un Estado Plurinacional e Intercultural. Secretaría Nacional de Planificación y Desarrollo-SENPLADES.

Ecuador. (20II). Agenda Política de la Defensa. Ministerio de Defensa Nacional.

Ecuador. (20I3). Política de Género de las Fuerzas Armadas del Ecuador. Ministerio de Defensa Nacional.

Ecuador. (2017). Cartilla de Género Fuerzas Armadas del Ecuador. Ministerio de Defensa Nacional.

Ecuador. (2021). Sistema Informático de Escrutinio y Resultados. Consejo Nacional Electoral.

Eichler, M. (20I4). Militarized Masculinities in International Relations. The Brown Journal of World Affairs, 2I (I), 8I-93.

El Comercio. (03.06.2018). Ecuador empieza alistamiento de 199 mujeres para el servicio militar. El Comercio.

Elshtain, J. ( 1 982). On beautiful souls, just warriors and feminist consciousness. Women's Studies International Forum, 5 (3-4), 34I-348.

Elshtain, J. (2005).Women and War. En Townshend, C. (Ed.). The Oxford History of Modern War. Oxford University Press. Enloe, C. (2000). Maneuvers:The International Politics of Militarizing Women's Lives. University of California Press.

Enloe, C. (20I4). Bananas, Beaches and Bases: Making Feminist Sense of International Politics. University of California Press. Ferguson, B. (202I). Masculinity and War. Current Anthropology, 62 (S23), I I 2-I 24.

Garrido, A. (202I). Análisis de género en los contextos de violencia organizada. Una mirada sociológica. Estudios Políticos, 62, 80-104.

Grant, R. (1992). The Quagmire of Gender and Internacional Security. En Peterson, S. (Ed.). Gendered States: Feminist (Re)Visions of International Relations Theory. Lynne Rienner Publishers.

Guyer, J.G. (2017). Libros Blanco de Defensa en Sudamérica: ¿Política Exterior o Política Doméstica? Revista Brasileira de Estudos de Defesa, 4 (2).

Hansen, L. (20I0). Ontologies, Epistemologies, Methodologies. En Shepherd, L. (Ed.). Gender Matters in Global Politics:A Feminist Introduction to International Relations (pp. 17-27). Routledge.

Hernández, R. (2017). Confrontando la Utopía Desarrollista: El Buen Vivir y La Comunalidad en las luchas de las Mujeres Indígenas. En Varea, S. y Zaragocin, S. (Eds.). Feminismo y Buen Vivir: Utopías Decoloniales (pp. 26-43). PYDLOS.

Herrera, K.P. (2020). Mujeres comando en la Policía Nacional. Instituto de Altos Estudios Nacionales.

Hooper, C. (1999). Masculinities, IR and the "Gender Variable": A Cost-Benefit Analysis for (Sympathetic) Gender Sceptics. Review of International Studies, 25 (3), 475-49I.

Iglesias, P.C., Urrutxi, L.D. y Arizti, N.B. (202I). Masculinidades alternativas: un modelo para alcanzar la transformación desde la educación social. Ciencia y Educación, 5 (I), I47-I58.

Iturralde, M. del C. (20I5). La mujer ecuatoriana en las Fuerzas Armadas: Un espejo de la sociedad. El Outsider, 3, 30-36.

Kronsell,A. (20I2). Gender, Sex, and the Postnational Defense. Oxford University Press.

Macas, L. (2010). Sumak Kawsay: La vida en plenitud. América Latina En Movimiento, 452, I4- 16.

Maingueneau, D. (20I5). Discurso e análise do discurso. Parábola Editorial.

Meza, G. (2004). Rol de la mujer en las Fuerzas Armadas del Ecuador y su participación en las actividades militares. Facultad Latinoamericana de Ciencias Sociales FLACSO-Ecuador.

Morales, X., Barba, R., González, C., Zapata,J.y Norona, D. (2017). Mujeres en las Fuerzas Armadas: el caso del ejército ecuatoriano. Revista de Ciencias de Seguridad y Defensa, 4, I25-I3I.

Narain, S. (20I4). Gender in International Relations: Feminist Perspectives of J. Ann Tickner. Indian Journal of Gender Studies, 2 I (2), I79-197. 
OIG-CEPAL. (202I). Tiempo total de trabajo. Observatorio de lgualdad de Género.

ONU-PNUD. (1994). Informe sobre Desarrollo Humano. Oxford University Press.

Orbe, K. (2016). Mujeres en las Fuerzas Armadas ecuatorianas: avances y limitaciones en la igualdad de oportunidades (2008-20 I 4). Estado \& Comunes, Revista de Políticas y Problemas Públicos, 2 (3), 37-50.

Orlandi, E. (20I2). Análise de discurso : princípios \& procedimentos. Pontes.

Orta, R. y Alaminos, Á. (202I). The conflict in democratic republic of the congo: Monusco's role on the eradication of sexual violence against women. Relacoes Internacionais No Mundo Atual, I (30), 4I-73.

Palomino, S. (28.06.202I). Pouco a comemorar na América Latina, onde ser LGBTQIA+ é ser alvo. El País.

Peterson, V.S. (2004). Feminist Theories Within, Invisible To, and Beyond IR. Brown Journal of World Affairs, I0 (2), 35-46.

Radcliffe, S.A. (2017). Género y Buen Vivir: Desigualdades Interseccionales y la Descolonización de las Jerarquías Persistentes. En Varea, S. y Zaragocin, S. (Eds.). Feminismo y Buen Vivir:Utopías Decoloniales (pp. 75-90). PYDLOS

Rebelo, T.R. (20I2). Lentes de gênero para as missões de paz: desconstrução de discursos e reflexões sobre práticas generificadas. Cultura Acadêmica.

Redacción. (03.07.202I). La controversia por el plan de Ucrania de que las mujeres soldado marchen con tacones. BBC Mundo.

Runyan, A.S. y Peterson, V.S. (20I4). Introduction: Gender and Global Issues. En Runyan, A.S. y Peterson, V.S. (Eds.). Global Gender Issues in the New Millennium (pp. I-38). Westview Press.

Santos, B. (2018). Na oficina do sociólogo artesão: as epistemologias do sul para superar a opressão capitalista, colonialista e patriarcal. Cortez.

Scott, J. (2018). Gender:A Useful Category of Historical Analysis. En Scott, J. Gender and the Politics of History (p. 288). Columbia University Press.

Shepherd, L.J. (20I0). Mujeres, conflictos armados y lenguaje: el género, la violencia y el discurso. Revista Internacional de La Cruz Roja, 877, I-I8.

Sjoberg, L. (2009). Introduction to security studies: Feminist contributions. Security Studies, I8 (2), I83-2I3.

Sjoberg, L. y Gentry, C.E. (2007). Mothers, monsters, whores: women's violence in global politics. Zed Books.

Solhjell, R. (20I4). Sin mujeres por aquí:Discursos de género en las Operaciones de Paz de Naciones Unidas. Relaciones Internacionales, (27), 97-I I6.

Stern, M. y Zalewski, M. (2009). Feminist fatigue(s): Reflections on feminism and familiar fables of militarisation. Review of International Studies, 35 (3), 6 I I-630.

Sylvester, C. (20I5). Contending with Women and War. Politics and Gender, II (3), 586-595.

Tapscott, R. (2020). Militarized masculinity and the paradox of restraint: mechanisms of social control under modern authoritarianism. International Affairs, 96 (6), I 565-I 584.

Tellería, L. (2009). Mulher, Forças Armadas e Missões de Paz na Região Andina. En Kalil Mathias, S. (Ed.). Sob o signo de Atena: gênero na diplomacia e nas Forças Armadas (pp. 5I-8I). UNESP.

Tickner, A. (1992). Gender in International Relations. Columbia University Press.

Tickner,A. y Sjoberg, L. (20I7). Feminism. En Dunne, T., Kurki, M. Smith, S. (Eds). International Relations Theories: Discipline and Diversity. Oxford University Press.

Tickner,A. (1997).You Just Don't Understand:Troubled Engagements Between Feminists and IR Theorists. International Studies Quarterly, 4I (4), 6I I-632.

True, J. (2020). Violence Against Women:What Everyone Needs to Know. Oxford University Press.

Ulloa, C. (2020). Chávez, Correa y Morales: discurso y poder. UDLA.

Via, S. (2010). Gender, Militarism, and Globalization: Soldiers for Hire and Hegemonic Masculinity. En Sjoberg, L. y Via, S. (Eds.). Gender, War and Militarism: feminist perspectives (pp. 42-57). Praeger.

Walsh, C. (20I5). Affirmative action(ing)s and postneoliberal movement in South America and Ecuador. Cultural Dynamics, 27 (I), |9-4I.

Whitworth, S. (1997). Feminist Theories and International Relations. En Feminism and International Relations. Palgrave Macmillan.

Yang,Y. (2020).What's Hegemonic about Hegemonic Masculinity? Legitimation and Beyond. Sociological Theory, 38 (4), 318-333.

Young, I. (2003). The Logic of Masculinist Protection: Reflections on the Current Security State. Signs, 29 (3), I-25.

Zaldumbide, M. (2020). Mujer, paz y seguridad: implementación de la Resolución I 325 del Consejo de Seguridad en Ecuador. Flacso Ecuador.

Zaragocín, S. (20I7). Feminismo Decolonial y Buen Vivir. En Zaragocín, S. y Varea, S. (Eds.). Feminismo y Buen Vivir:Utopías Decoloniales (pp. 17-25). PYDLOS.

Zaragocín, S. (20 18). A Soldier's Buen Vivir: Social Inclusion in the Ecuadorian Armed Forces. Bulletin of Latin American Research, 37 (4), 434-448. 


\section{RELACIONES INTERNACIONALES}

Revista académica cuatrimestral de publicación electrónica Grupo de Estudios de Relaciones Internacionales (GERI)

Universidad Autónoma de Madrid, España

https://revistas.uam.es/relacionesinternacionales

ISSN 1699 - 3950

f facebook.com/RelacionesInternacionales

3. twitter.com/RRInternacional

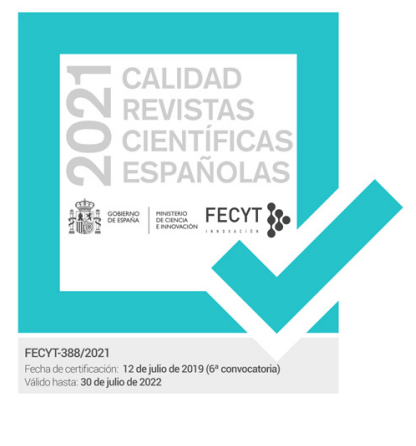

